\section{COMMUNITIES ENCOURAGED TO HELP SMOKERS QUIT}

On this year's No Smoking Day Health Secretary Andrew Lansley announced new ambitions to tackle the substantial public health harms from tobacco.

The Government has published Healthy lives, healthy people: a tobacco control plan for England which sets out how tobacco control will be delivered over the next five years.

Local communities will take a leading role in reducing smoking rates. The plan confirms action to end eye catching tobacco displays in shops which encourage young people to start smoking.

'Over eight million people in England still smoke and it causes more than 80,000 deaths each year', said Mr Lansley. 'We want to do everything we can to help people to choose to stop smoking and encourage young people not to start in the first place. We will help local communities to take a comprehensive approach to reducing smoking so we can change social attitudes to smoking.

By the end of 2015 the Government hopes to reduce smoking rates from $21.2 \%$ to $18.5 \%$ or less among adults.

\section{VIEWS ON SCOPE OF}

\section{PRACTICE REQUESTED}

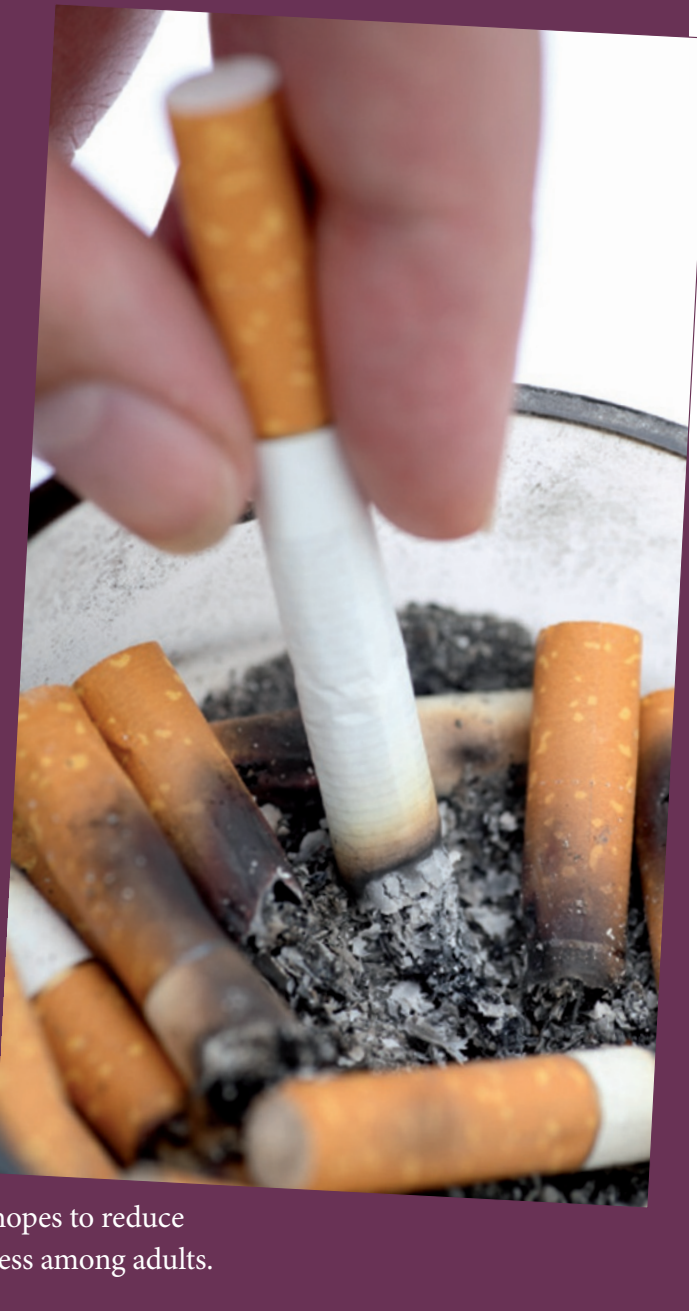

The General Dental Council (GDC) wants to hear from dental professionals as part of its review of Scope of practice, one of the GDC's key documents.

Scope of practice was first published in January 2009 and clearly sets out the skills and abilities that each registrant group should have, as well as listing the additional skills registrants may develop after registration.

An online feedback exercise is being launched to find out whether Scope of practice has achieved its original aims and whether the lists still accurately reflect the scope of practice for all registrant groups.

Questions the GDC is asking include:

- Do dental professionals agree the

lists accurately reflect the work that

should be carried out by a particular registrant group?

- Are there any skills that dental professionals think should be removed from these lists?

- What barriers have dental professionals encountered when trying to increase their scope of practice?

Dental professionals can take part through the GDC's website at https://web. questback.com/thegeneraldentalcouncil/ 50gsubr7ow/

\title{
FOUR PRACTICES WIN £500
}

Four UK dental practices have each won $£ 500$ in the British Dental Trade Association’s (BDTA's) Change4Life campaign.

The Robert Wakefield Dental Surgery, Driffield; Ghyllmount Dental, Penrith; Naidu \& Naidu Dental Care, Essex and The Dental Care Centre, London were selected at random from over 2,000 completed questionnaires.

The 'Kick out the sweets, bring on the treats' Change4Life campaign involved dental practices displaying posters, encouraging patients to complete the questionnaires and presenting younger patients with colourful stickers.

'This was a perfect $\quad$ way to get children interested in dental health, said Tony Reed, BDTA Executive who promoted the

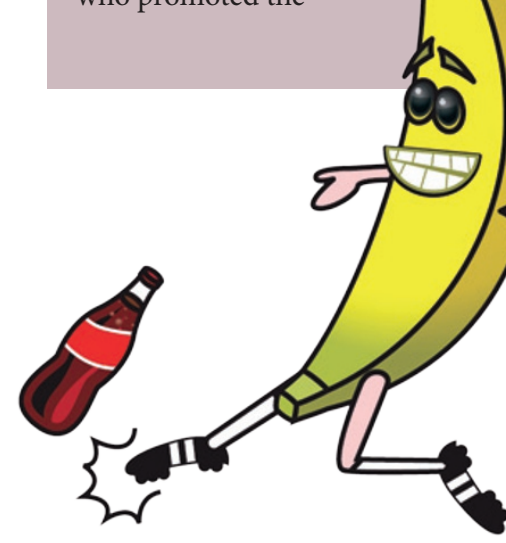
Director. 'Thank you to all the practices

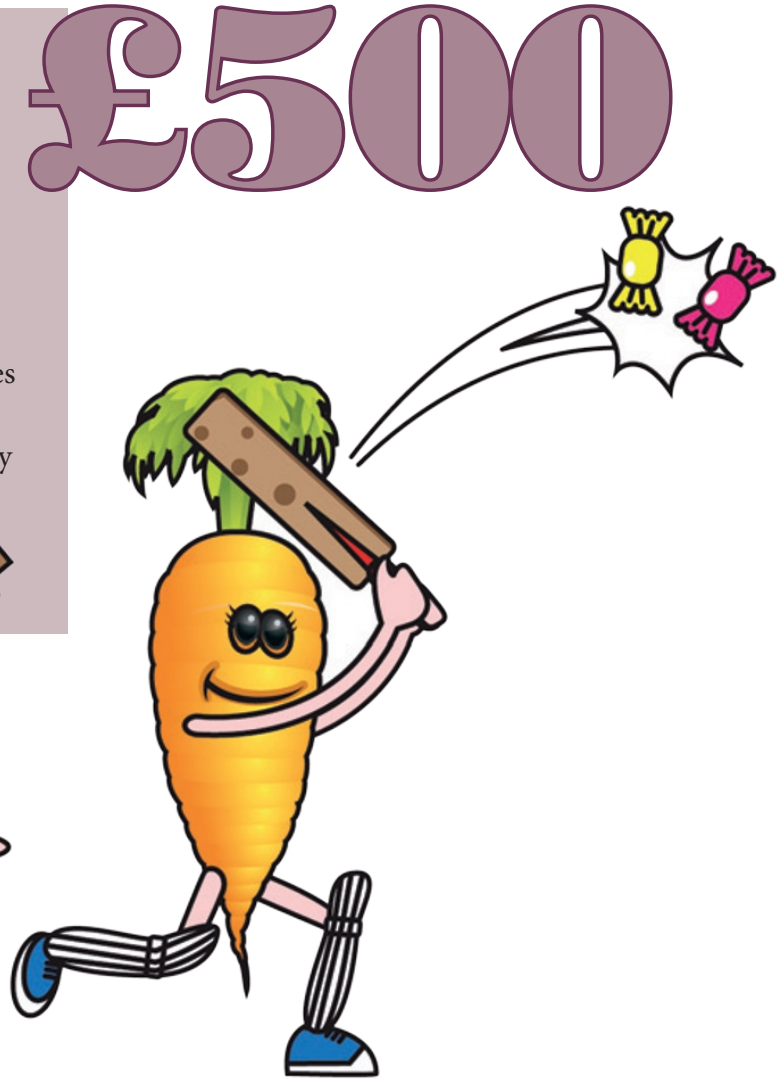

